\title{
Investigating ramp gradients for humps on railway platforms
}

1 Taku Fujiyama PhD

Senior Lecturer, University College London, London, UK

2 Craig Childs $\mathrm{PhD}$

Research Fellow, University of Strathclyde, Glasgow, UK
3 Derrick Boampong PhD

Laboratory Manager, University College London, London, UK

4 Nick Tyler CBE, PhD, ARCM, CEng, FICE, FRSA, FREng Chadwick Professor of Civil Engineering, University College London, London, UK
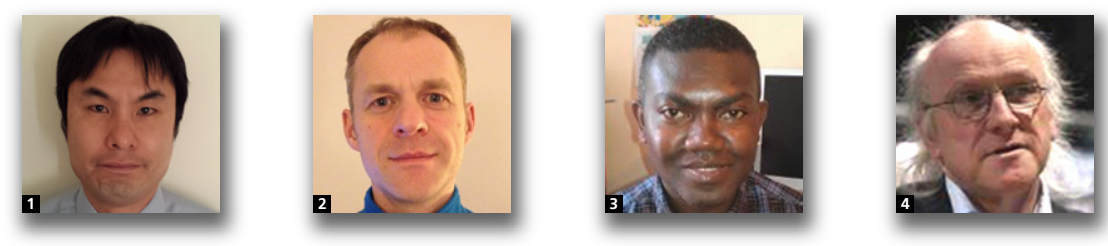

Horizontal and vertical gaps between the train and the platform are a major safety concern for railway passengers, especially for disabled passengers. London Underground is implementing a programme to install platform humps to remove vertical differences between the train and the platform. In order to properly design platform humps, this study empirically investigated the effects of the design factors of the ramps, namely the slope and cross-fall gradients, on disabled passengers. The investigation consisted of two experiments: one where 20 participants were asked to walk on simulated slopes, and the other where 25 participants were asked to board or alight from the simulated train from or onto the slopes. The slope gradients tested were $3.0 \%(1: 33), 5.2 \%(1: 19)$ and $6.9 \%(1: 14)$ with the cross-fall gradients $1.5 \%(1: 67), 2.0 \%(1: 50)$ and $2.5 \%(1: 40)$. The results showed that the slope gradient does not largely affect the participants' performance of longitudinal walking on the slopes or their subjective safety evaluation, but would cause additional difficulty for them to board/alight from the train from/onto the slope. This suggests that train doors should not stop next to the ramp. There was little evidence concerning the effects of the cross-fall gradient. The results provide useful information for designing platform humps.

\section{Introduction}

Horizontal and vertical gaps between the train and the platform are a big hazard in railway systems. The issue is significant in railways built in the nineteenth or early twentieth century but still in use. There is always a risk of passengers tripping or falling into the gap. Gaps especially affect disabled passengers, and are one of the main barriers that deter disabled and elderly passengers from using railways. In the UK, the Rail Vehicle Accessibility Regulations 2010 (RVAR 2010) (HMG, 2010) stipulate that if the gap between the edge of the door sill and the edge of the platform is more than $75 \mathrm{~mm}$ horizontally or more than $50 \mathrm{~mm}$ vertically, a boarding device is required for wheelchair users. There has been research which concluded that when the gap height and width are added together, the value should not exceed $200 \mathrm{~mm}$ (Atkins, 2004).

A gap consists of two components: a horizontal component and a vertical component. It is difficult to eliminate the horizontal component given that the shape of the platform edge is an arc, whereas that of the carriage is rectangular. The main cause of vertical gaps, however, is the platform regulations according to which existing platforms were built. Because the platform regulations were made a long time ago, they do not match the specifications of current trains and did not consider the importance of level access between the train and the platform. The vertical component can be reduced by a relatively simple solution: raising (or lowering) the platform level, but raising (or lowering) the whole platform may be costly. Therefore, London Underground has decided to introduce humps on platforms, across its network, in order to achieve level access at a certain part of the train/platform. By constructing a hump at the same part of the platform at every station of any line, it is possible to guarantee that, if a passenger boards by way of a door of a train from a hump, there will be a hump for the door when he/she alights.

Humps consist of several design factors, including the slope gradient, width and length of the top level part (upper 
landing). It is speculated that the width and the length of the upper landing should be decided based on the size and manoeuvrability of wheelchairs and their users. The safety concerns lie mainly in the dimensions of the ramp. The following points need to be considered.

- Passengers, especially disabled passengers, should be able to walk safely and comfortably on the ramp

- Railway platforms often have a lateral (cross-fall) gradient for safety and drainage reasons. When a ramp is built along the platform (which means that the longitudinal direction of the ramp is parallel to the track), the ramp would have not only a longitudinal gradient (slope gradient) but also a lateral gradient (cross-fall gradient).

- Suppose a hump is to be introduced in a station where the vertical difference between the train and the platform levels is large. The upper landing is located at a certain door(s) of the train. If the train has many doors, which means that the distance between two adjacent doors is small, the lower end of the slope may reach a door adjacent to the one at the upper landing (see Figure 1). In this case, designers need to choose between $(a)$ increasing the gradient of the slope so that the slope does not reach adjacent doors; (b) keeping the slope gradient but admitting that passengers need to board/alight from/onto a sloped platform; or (c) inserting a middle landing to the slope so that the landing is at the door. The information regarding the effects of the sloped platform on the boarding and alighting of passengers would be valuable to make a decision on this issue.

- It is speculated that congestion may affect safe and comfortable use of the hump, but this study did not consider this because its primary focus is the effects of the design factors of the hump. For the same reason, this study does not consider the effects of surface materials either.

\section{Existing studies, regulations and guidelines}

There have been several studies on the gradients of ramps. Templer (1992) concluded that ramps steeper than 1:8 (12.5\%)

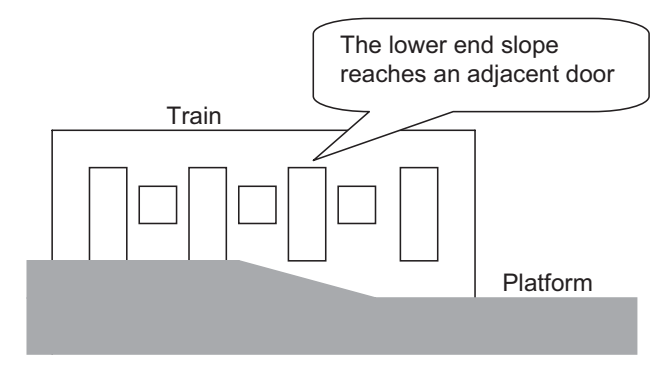

Figure 1. Schematic representation of situation where lower end of a slope reaches an adjacent door are inaccessible or difficult to use from the viewpoint of elderly and disabled passengers. He recommended a maximum slope of $1: 10(10 \%)$ for a height greater than 3 in $(7.6 \mathrm{~cm})$ and $1: 12$ $(8 \cdot 3 \%)$ for a height greater than 6 in $(15.2 \mathrm{~cm})$ but less than $9 \mathrm{ft}$ $(2.74 \mathrm{~m})$. He also pointed out that if a slope between the pavement and the carriageway at pedestrian crossings is lower than $1: 16(6 \cdot 3 \%)$, visually impaired people with a long cane on the pavement cannot detect the change of the surface, and therefore may stray into the carriageway. Indeed, 1:12 (8.3\%) has been set as the maximum gradient of ramps according to the standards of some countries including the USA and the UK (BSI, 2009; Department of Justice, 2010). This value was re-examined by Stanford et al. (1997), who concluded that it should remain. Based on interviews and observations, Leake et al. (1991) concluded that for wheelchair users a gradient in excess of 1:50 (2.0\%) should be avoided where possible, and for ambulatory disabled people the threshold can be increased to 1:25 (4.0\%). Ishida et al. (2006), who studied pavements from the viewpoint of wheelchair users, found that when the slope gradient exceeds 1:50 $(2.0 \%)$, subjective discomfort and the gradient have a linear relationship. Kim et al. (2010) investigated the effects of the ramp gradients ranging from 1:6 $(16 \%)$ to $1: 14(7 \%)$ on wheelchair users, but found that such effects were minor when the height was low $(15 \mathrm{~cm})$. Canale et al. (1991) recommended 1:6.7 (14.9\%), whereas Steinfeld et al. (1979) concluded that people with limited stamina, hemiplegics and quadriplegics may have difficulty with ramps steeper than 1:20 (5.0\%). As Stanford et al. (1997) pointed out, one reason for the variance among these acceptable limits of the gradient may be because different studies employ different samples.

In the UK, there are several standards regarding the slope gradient in railway stations and buildings. British Standards BS 8300:2009 'Design of buildings and their approaches to meet the needs of disabled people' (BSI, 2009) stated that the maximum gradient should be $1: 20(5 \%)$ for $10 \mathrm{~m}$; $1: 15(6.7 \%)$ for $5 \mathrm{~m}$; and $1: 12(8.3 \%)$ for $2 \mathrm{~m}$ or shorter. Although this clause is for ramp accesses to buildings, it is reasonable to assume that this is a recommendation for publicly accessible ramps and thus this should be used for designing platform humps. Accessible Train Station Design for Disabled People: A Code of Practice (DfT and TS, 2011) generally recommends a gradient of 1:20 or slower for ramps but also states that if, in existing stations, a ramp steeper than 1:12 is unavoidable, (the length of the ramp) should not be longer than $2 \mathrm{~m}$.' As for the cross-fall gradient, the British standard (BSI, 2009) states that a cross-fall gradient of any ramp should be not more than 1:50 $(2 \cdot 0 \%)$.

From observations of the existing literature, regulations and guidelines, the authors concluded that there have been studies on the slope gradient in the longitudinal direction, but no 
study on the slope with both longitudinal and cross-fall gradients. There has been no study on boarding/alighting the train from/onto the slope. This may be because there are few humps on railway platforms. Therefore, in order to realise properly designed humps, the effects of the design factors of the ramps, namely the slope gradient and the cross-fall gradient, were empirically investigated.

\section{Experiment}

The empirical investigation consisted of two experiments. The first experiment examined the longitudinal walk on slopes with longitudinal and cross-fall gradients, and the second studied alighting/boarding from the train onto sloped platforms. The empirical work took place in the Pedestrian Accessibility and Movement Environment Laboratory (Pamela) at University College London.

\subsection{Experiment 1: Longitudinal walk-on ramps}

In the first experiment (see Figure 2), the following three slopes were tested

- slope 1: slope gradient 3.0\% (1:33), horizontal length $8.40 \mathrm{~m}$, vertical ascent $0 \cdot 25 \mathrm{~m}$

- slope 2: slope gradient $5 \cdot 2 \%$ (1:19), horizontal length $4.80 \mathrm{~m}$, vertical ascent $0.25 \mathrm{~m}$

- slope 3: slope gradient 6.9\% (1:14), horizontal length $3.60 \mathrm{~m}$, vertical ascent $0.25 \mathrm{~m}$.

Each slope had a cross-fall gradient of $1 \cdot 5 \%, 2 \cdot 0 \%$ or $2 \cdot 5 \%$. The cross-fall gradient was changed in the course of the experiment. Participants were asked to test each cross-fall gradient for each slope. This means there were nine slopes with different slope/cross-fall gradients (three slope gradients $\times$ three cross-fall gradients). These gradients were chosen according to existing vertical gaps at the train-platform interface of London

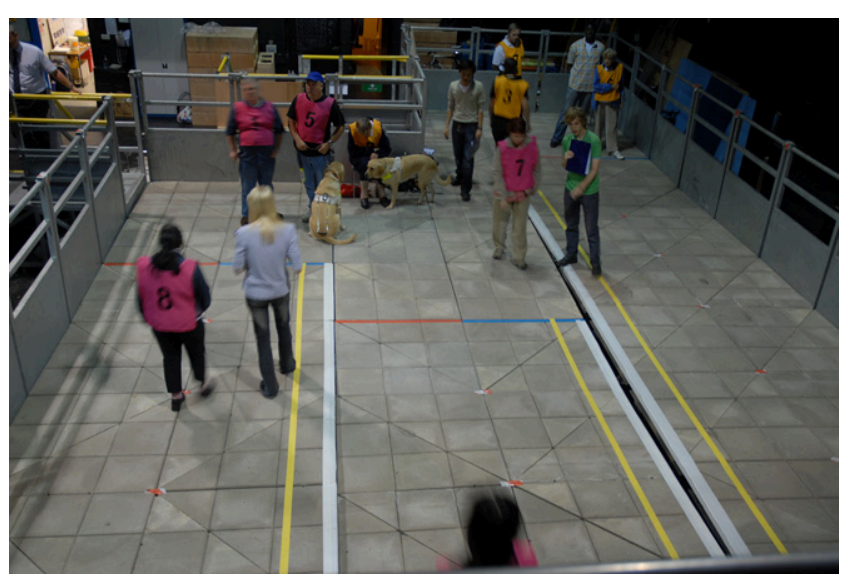

Figure 2. A photograph taken during experiment 1
Underground, existing regulations and guidelines and the capability of the Pamela platform. There was a $1.20 \mathrm{~m}$ long flat landing space next to each end of the slope. The width of each slope was $2.40 \mathrm{~m}$. Using video cameras on the ceiling of the laboratory, the behaviour of the participants was recorded.

For each slope, all the participants except those with visual impairment made two round trips from the mark at the lower landing to the mark at the upper landing space and to the mark at the lower landing. Those with visual impairment made one round trip only. After completing the walk on each slope, each participant was asked about his/her subjective evaluation of the slope regarding their perception of safety. Each participant was asked to choose one of the following options: I felt entirely safe (1); I felt safe but needed to be a bit careful (2); I felt a little unsafe; needed to be quite careful (3); I felt unsafe (4); or I felt frightened about my own safety (5). The question and the analysis method were the same as those used by Atkins (2004).

There were 20 participants, consisting of five groups, namely 'wheels' (five participants), 'visually impaired people (VIP)' (eight participants), 'mobility restrictions' (four participants), 'shoes' (two participants) and 'wheelchair' (one participant). 'Wheels' consisted of two participants with a pram and three with a suitcase with wheels. 'VIP' included two participants with a guide dog, three with a long cane and three with midrange visual impairment. 'Mobility restrictions' included two people who usually use a crutch when going out and two who limp when walking. 'Shoes' included two people with highheeled shoes. 'Wheelchair' included a person with a manually self-propelled wheelchair.

\subsection{Experiment 2: Boarding/alighting the train from/onto the ramp}

Experiment 2 was designed to investigate the effects of the slope gradient as well as horizontal and vertical differences in the gap on behaviour and perceived safety of passengers boarding/alighting the train from/onto the sloped platform (see Figure 3). Three slopes were set up with different slope gradients: $3 \cdot 0 \%(1: 33), 5 \cdot 2 \%(1: 19)$ and $6 \cdot 9 \%$ (1:14). At the side of each slope was placed a wooden platform, which had three boarding/alighting (stepping) places: one where the vertical difference between the platform and the slope was $50 \mathrm{~mm}$, another $150 \mathrm{~mm}$ and the third $250 \mathrm{~mm}$. This meant that nine stepping places were set. At each stepping place, a measurement line was set on the slope $0.30 \mathrm{~m}$ away from the slope edge, and another on the platform $0.30 \mathrm{~m}$ away from the platform edge. At each stepping place, a mark was located at a point $1.20 \mathrm{~m}$ away from the platform edge and another $1.20 \mathrm{~m}$ away from the slope edge, and participants were asked to start and stop walking at a mark, rather than on a measurement line. At each stepping place, there was a horizontal gap with a width of $75 \mathrm{~mm}$ between the slope and the platform, but in the 


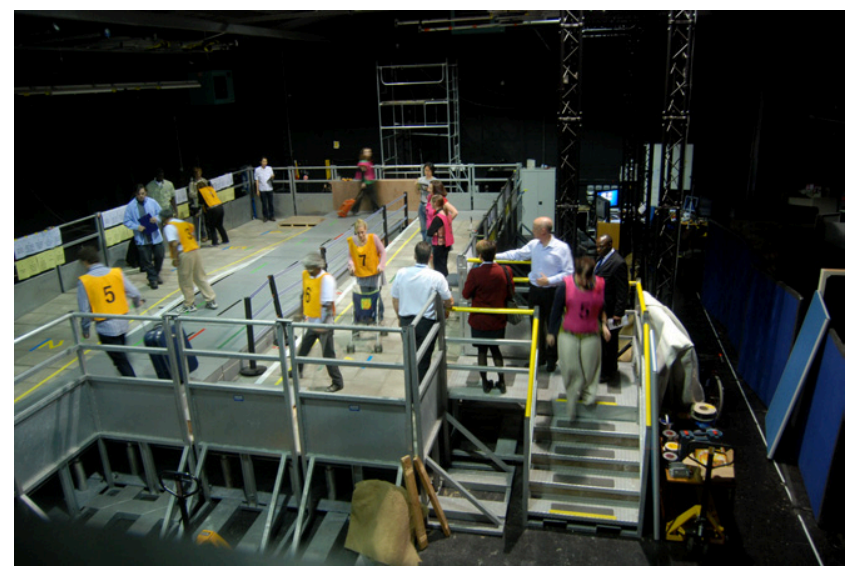

Figure 3. A photograph taken during experiment 2

course of the experiment the width was changed to $150 \mathrm{~mm}$ and then $225 \mathrm{~mm}$. Figure 4 explains the experiment settings. Because there were nine stepping places, it was possible to test $3 \times 9=27$ steps with different combinations of slope gradient and horizontal and vertical differences. The reference values of $50 \mathrm{~mm}$ for vertical differences and $75 \mathrm{~mm}$ for horizontal differences were set according to RVAR 2010. Note that there was no cross-fall gradient on any slope.

At each stepping place, participants were asked to walk from the mark on the slope to the mark on the platform and then back to the mark on the slope. Participants except those in the 'VIP' group were asked to complete the walking trial twice. Those in the 'VIP' group were asked to complete it once. Each participant was also asked about his/her perception of safety after completing the walk at each step in the same manner as in experiment 1 (see Figure 4).

There were 25 participants, consisting of four groups, namely 'wheels' (six participants), 'VIP' (12 participants), 'mobility restrictions' (four participants) and 'shoes' (three participants). 'Wheels' consisted of two participants with a pram and four with a suitcase with wheels. 'VIP' included three participants with a guide dog, six with a long cane and three with mid-range visual impairment. 'Mobility restrictions' included three people who use a crutch and one who limps. 'Shoes' included three people with high-heeled shoes. The degree of the disability of each group is the same as in experiment 1 .

\section{Data analysis}

\subsection{Experiment 1}

For each type of slope, the time taken by each participant to walk on the slope was measured. Using the videos captured by the cameras on the ceiling of Pamela, the difference between the two timings was calculated: when the centre of the participant's body passed one end of the slope and when it passed the other. By dividing the horizontal length of the difference by the time difference, the walking speed was calculated. Using SPSS version 20, a two-way analysis of variance (Anova) (repeated measure) was performed to examine the effects of the slope and cross-fall gradients on the ascending and descending walking speeds.

In addition, deviation of each participant on each slope was calculated. Deviation measurement lines were set every $1.20 \mathrm{~m}$ from the beginning to the end of the slope. On the video, how much the centre of each participant's body deviated from the previous deviation measurement line was measured.

$$
d_{i}=\left|D_{i}-D_{i-1}\right|
$$

where $d_{i}$ is the deviation at the deviation measurement line (i) (unit: metres) and $D_{i}$ is the lateral distance from the centre of the slope to the centre of the body at the deviation measurement line ( $i$ ) (unit: metres).

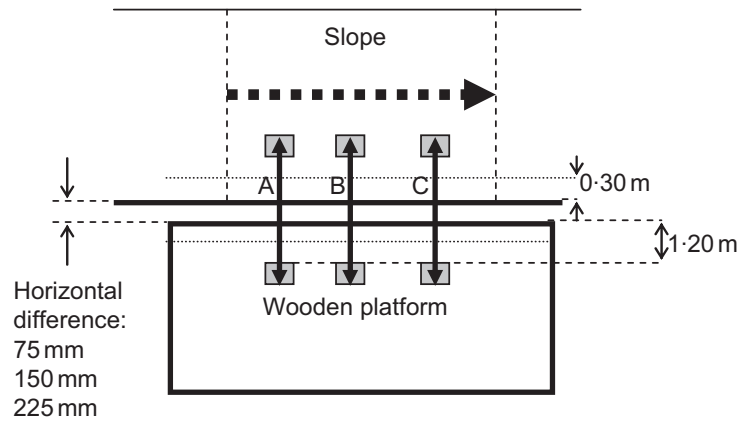

Vertical difference at stepping places A: $250 \mathrm{~mm}$

B: $150 \mathrm{~mm}$

C: $50 \mathrm{~mm}$

Mark

Measurement line

Figure 4. A schematic representation of the setting of experiment 2 
The measurement of deviation was conducted by identifying the nearest measurement point on the line to the point where the centre of the body passed. Measurement points were either the centre or an edge of the concrete block on the platform. Because the size of the concrete block of the Pamela platform is $0.40 \mathrm{~m}$ square, there are measurement points every $0.20 \mathrm{~m}$ on the deviation measurement line, thus deviation readings are $\{0.00 \mathrm{~m}, 0.20 \mathrm{~m}, 0.40 \mathrm{~m}, 0.80 \mathrm{~m} \ldots\}$.

The average deviation for each type of slope was calculated by

$$
\bar{d}=\frac{\sum_{i} d_{i}}{L}
$$

where $L$ is the horizontal length of the slope.

\subsection{Experiment 2}

Using the videos, the difference between the two timings was calculated: when the centre of the participant's body passed the measurement line on the slope and when it passed the other mark on the platform. Multivariate Anova (Manova) was performed to investigate the effects of the slope gradient, the vertical difference and the horizontal difference on the times taken to board and alight.

In the experiment, participants sometimes got stuck at the step or refused to try because they perceived the gap was too large. In these cases, the trial was recorded as a 'failure'.
Participants sometimes managed to board but could not alight. In that case, the trial was also recorded as a failure. Note that all the participants except the visually impaired were asked to make two trials at each stepping place. If a participant could not complete in both trials, 'failure' was recorded for each trial.

\section{Results}

Because of limitation of space, only notable results are presented here.

\subsection{Experiment 1}

The results of the Anova showed that there was no significant effect of the cross-fall gradient on the ascending or descending walking speeds with $p$-values of 0.72 and 0.44 , respectively. For the slope gradient, significant effects were observed for the ascending $(p<0.05)$ but not for descending ( $p=0.38)$ slopes.

In the experiment, each participant was asked to evaluate their perception of safety for each slope (see Section 3.1). Figure 5 shows the percentages of the participants in each participant group who scored 3 or more in the answer to the question regarding the perception of safety to the total number of participants by slope gradient. The wheelchair group shows an increase in the perception when the gradient increases from $5 \cdot 2 \%$ to $6 \cdot 9 \%$. Because the answer keys to the questions were in one dimension (the perception of safety), the average of the participants' scores was calculated.

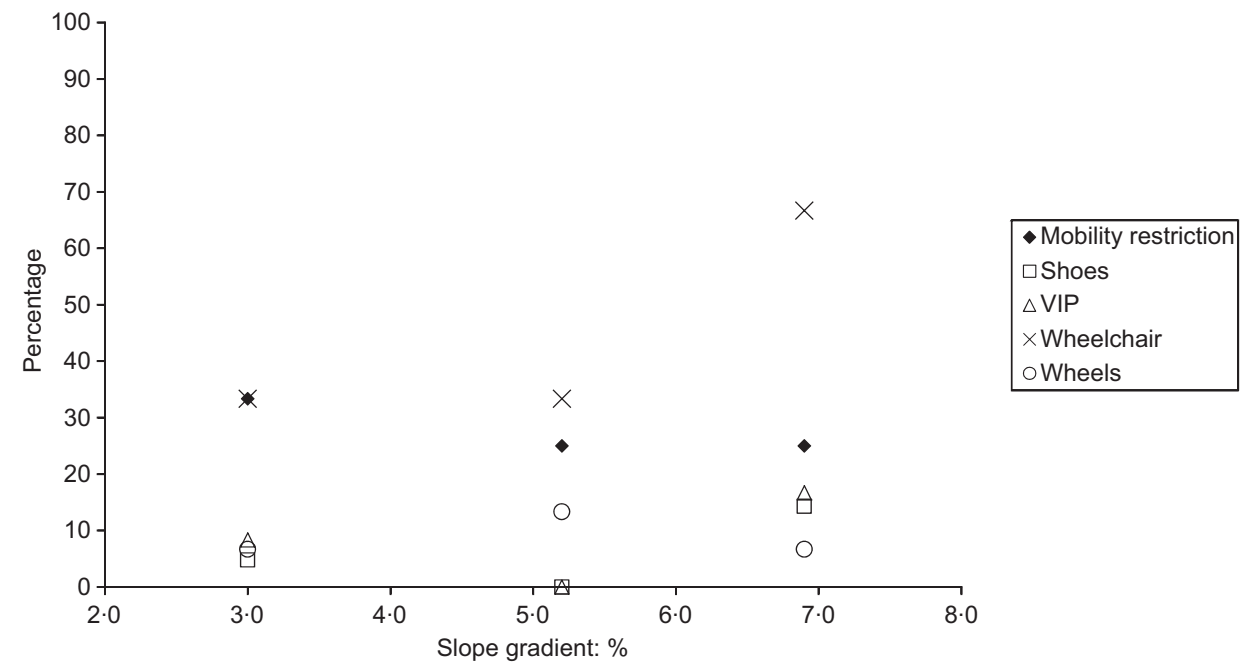

Figure 5. Percentages of the participants in each participant group who scored 3 or more to the question regarding perception of safety by slope gradient 


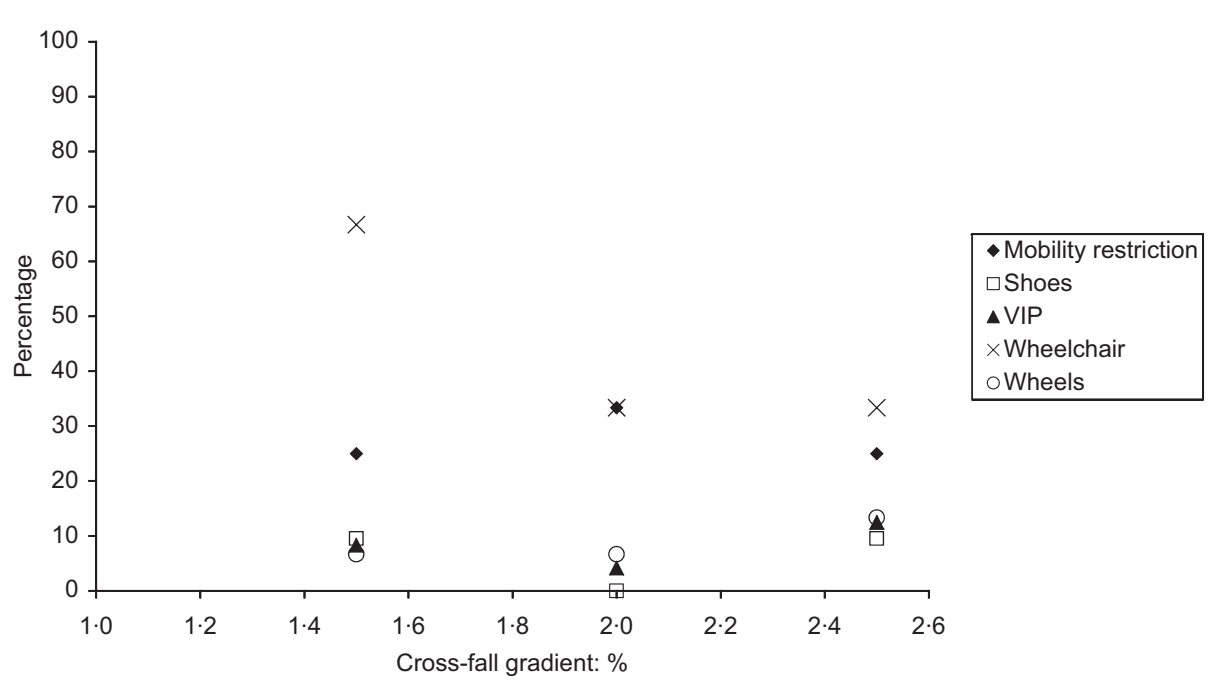

Figure 6. Percentages of the participants in each participant group who scored 3 or more in answer to the question regarding perception of safety by cross-fall gradient

Figure 6 shows the percentages of the participants in each participant group who scored 3 or more to the question regarding the perception of safety by cross-fall gradient. Effects of the cross-fall gradient are not clearly seen in the figure.

Figure 7 shows the average deviations of each participant group divided by cross-fall gradient when ascending. The group of visually impaired people shows a high value of deviation, but from the figures the effects of the cross-fall gradient are not clear.

\subsection{Experiment 2}

The results of the Manova show that neither the slope gradient, nor the vertical difference, nor the horizontal difference had significant effects on time taken to alight, with $p$-value being $0.23,0.63$ and 0.76 , respectively. This is the case for the

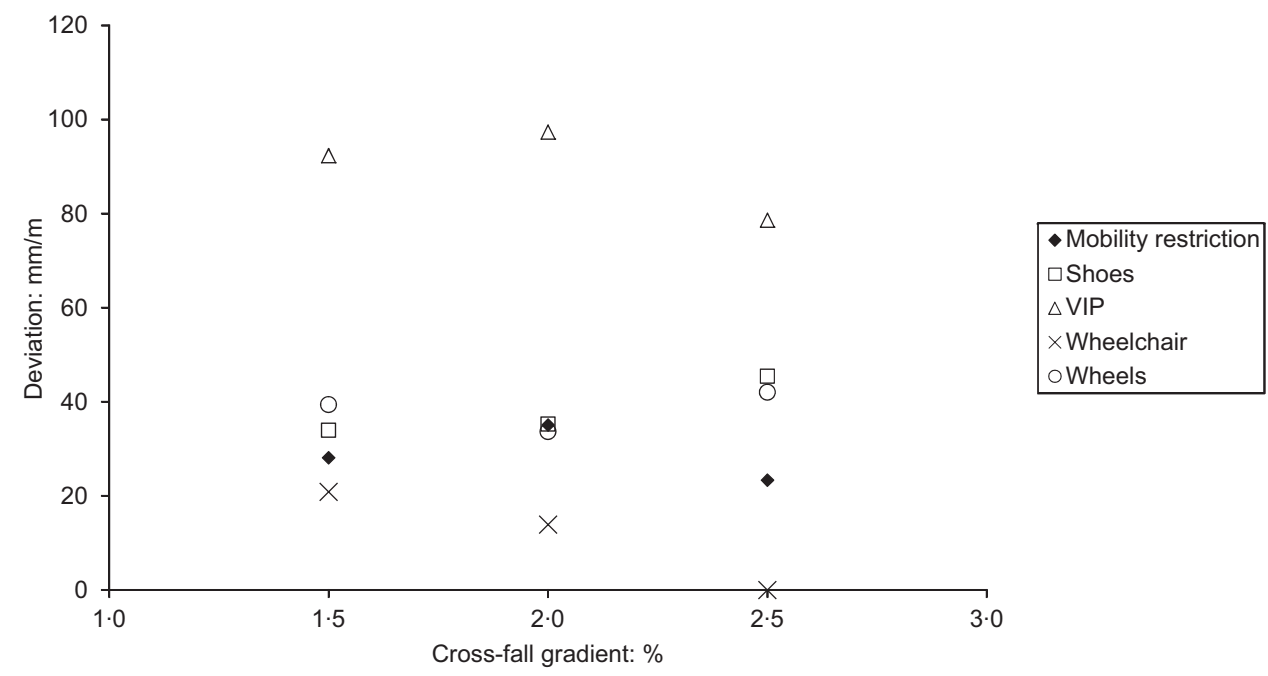

Figure 7. Average deviations of each participant group by cross-fall gradient when ascending 


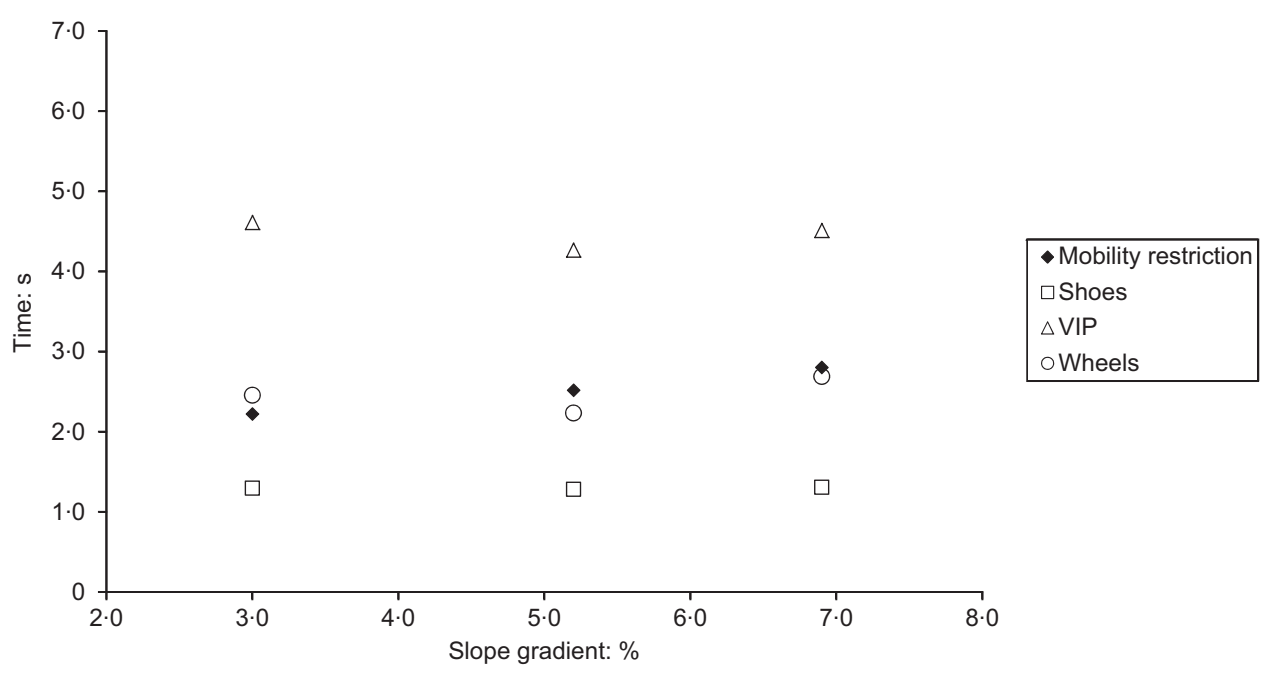

Figure 8. Average times taken to alight by each participant group

time taken to board, with $p$-value for the slope gradient, the vertical difference and the horizontal difference being 0.05 , $0 \cdot 74$ and 0.07 , respectively. Figure 8 , which shows the times taken for alighting, confirms this result.

Figure 9 shows the percentages of the participants in each participant group who scored 3 or more to the question regarding the perception of safety by slope gradient. The figure shows that the effects of the slope gradient are not clear, except for the shoes group who show an inverse trend.
Note that the shoes group included the participants with high-heeled shoes. In comparison, Figure 10 shows the percentages by vertical difference. Interestingly, the figure clearly shows, in contrast, that an increase of the vertical difference contributes to a higher score.

Figure 11 shows the percentages of failed trials to the total number of the trials of different participant groups by slope gradient. The percentage of the visually impaired participants increases according to the slope gradient.

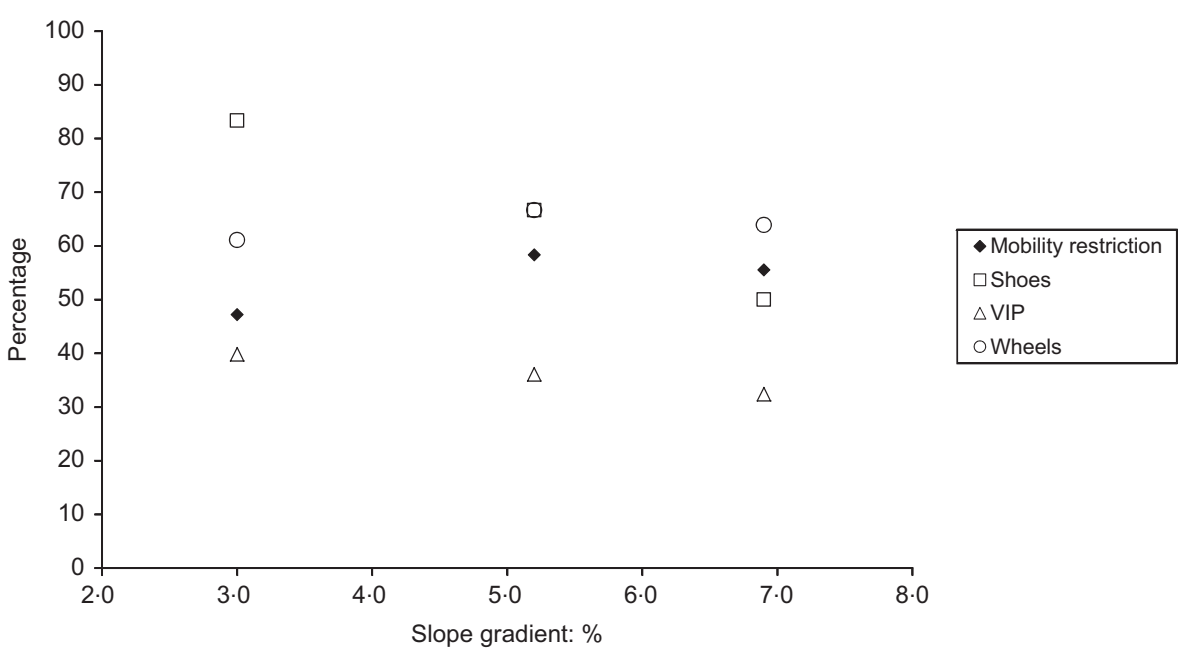

Figure 9. Percentages of the participants in each participant group who scored 3 or more to the question regarding the perception of safety by slope gradient 


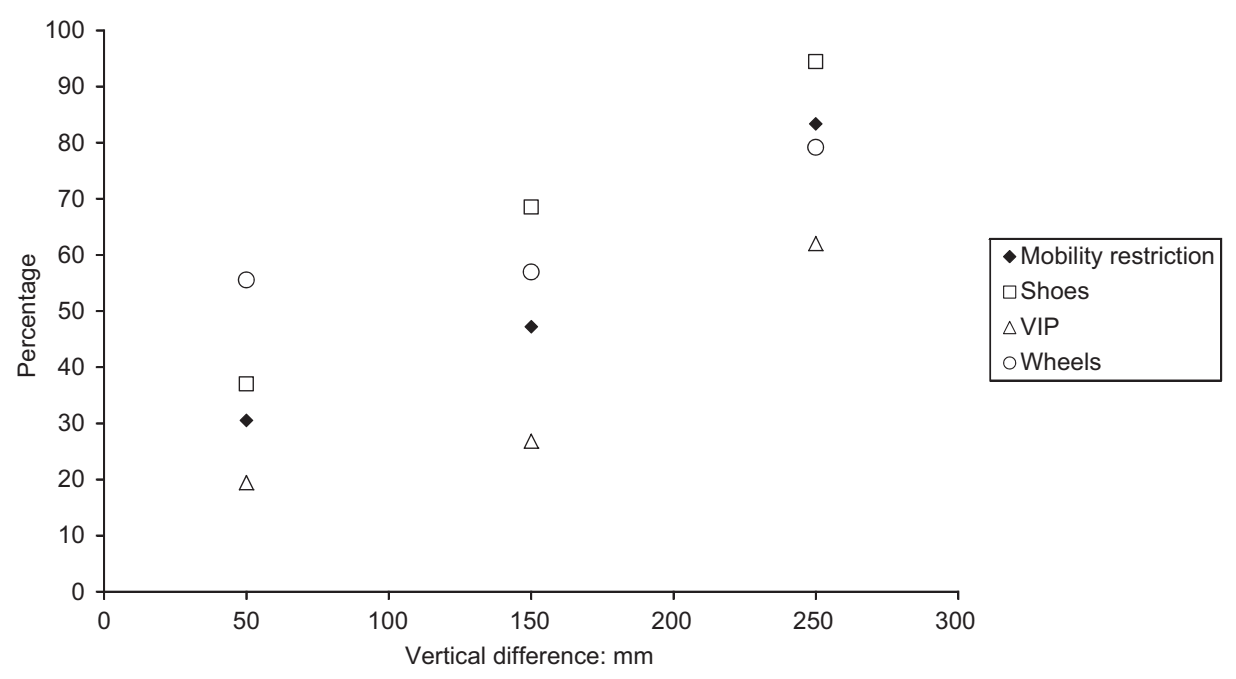

Figure 10. Percentages of the participants in each participant group who scored 3 or more to the question regarding the perception of safety by vertical difference

Figure 12 shows the percentages of failed trials to the total number of the trials of the mobility restriction group by slope gradient and vertical difference. The figure suggests that, for the vertical height of $150 \mathrm{~mm}$, an increase of the slope gradient contributes to an increase of the percentage.

\section{Discussion}

This study examined the effects of the slope and cross-fall gradients of the platform hump on the boarding and alighting of disabled passengers and their perception of safety. First, the results of the question about perception of safety in experiment 1 (Figure 5) show that overall, the effects of the slope gradient were not clearly seen, and indeed the averages scores of the answers were 3 or less. Score 3 represents 'I felt a little unsafe; needed to be quite careful'. This suggests that an increase of the slope gradient does not greatly contribute to an increase of perception of safety. Although the result of the Anova in experiment 1 implies that the slope gradient would affect the

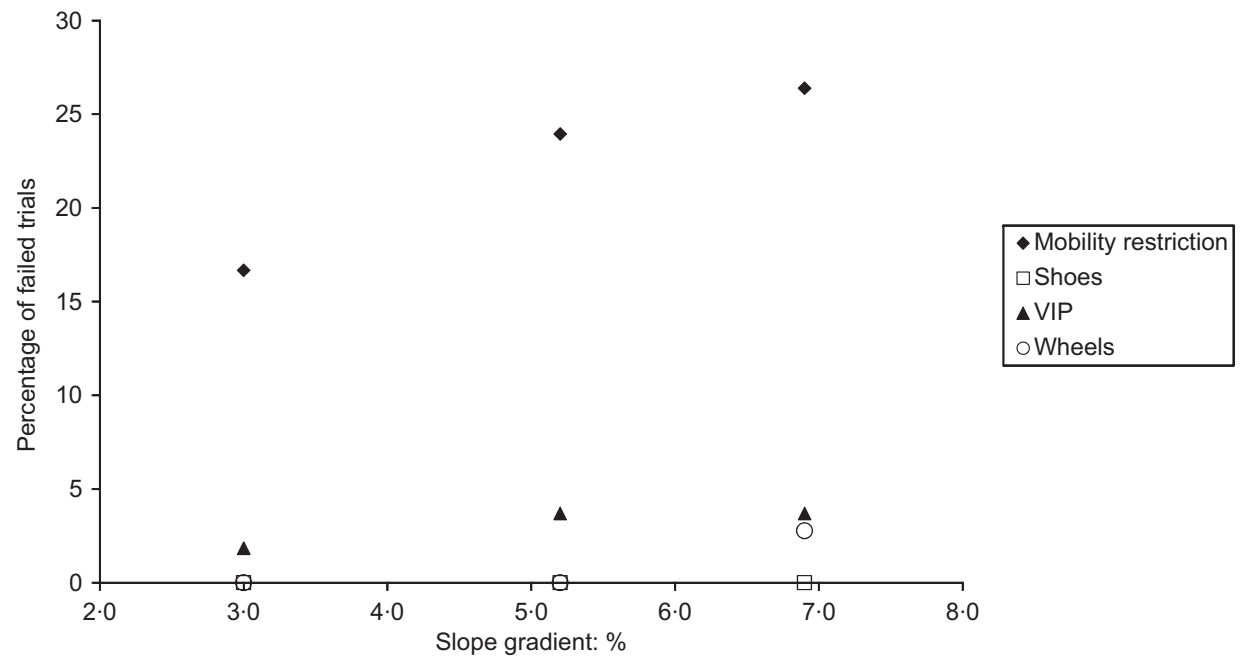

Figure 11. Percentage of failed trials to total trials of each participant group by slope gradient 


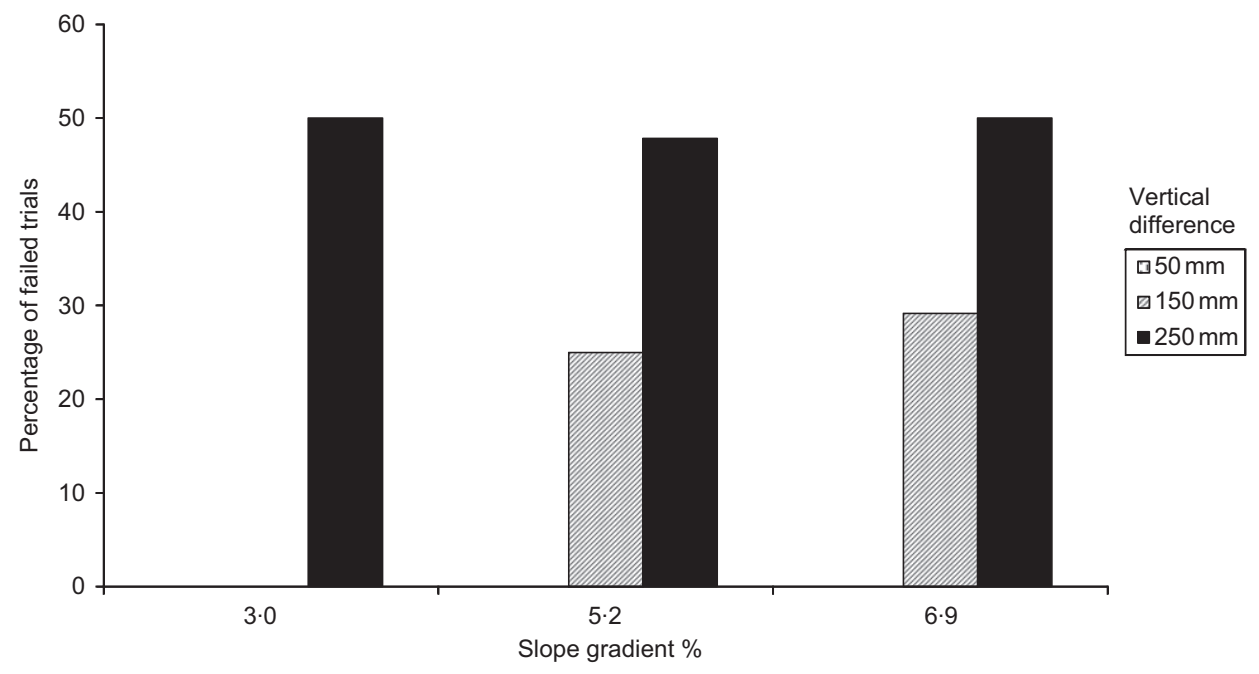

Figure 12. Percentage of failed trials to total of the mobility restriction group trials by slope gradient and vertical difference

ascending walking speed, safety is more important than the walking speed.

In experiment 2, it was observed that the perception of safety did not change according to the slope gradient (Figure 9) as much as it did for the vertical difference (Figure 10). In addition, Figure 8 and the results of the Manova in experiment 2 suggest that the slope gradient did not significantly affect the time taken to alight. However, the percentage of failed trials in experiment 2 suggests that an increase of the slope gradient may have affected the mobility restriction group (Figure 11). A detailed analysis leads to the observation that the percentage increased for the vertical height of $150 \mathrm{~mm}$ (Figure 12). For the other vertical heights, an increase of the slope gradient did not affect the percentage. Indeed, because no participant failed at the $50 \mathrm{~mm}$ height and half of the trials were failed at the $250 \mathrm{~mm}$ height, the $150 \mathrm{~mm}$ height can be considered as a threshold. This means that the slope gradient increased the percentage of failed trials for the vertical height that was around such a threshold. These results suggest that the slope gradient was, by itself, not the main factor that affects performance and perception of safety, but may have caused additional difficulty. When physically less capable people are stretching their capability to board or alight, the slope gradient would affect their performance.

An implication of the results above is that it could be recommended that doors should not stop next to a slope (Figure 1) because boarding or alighting the train to/from the ramp would add additional constraints for physically less capable people, whereas the results of experiment 1 showed that, within the range of the tested gradients, an increase of the slope gradient did not largely affect the perception of safety (Figure 5). This suggests that even though the slope gradient becomes steep, the slope length should not be so long that the slope would reach an adjacent door.

Regarding the cross-fall gradient, the perception of safety did not greatly vary according to the cross-fall gradient (Figure 6). The result of the Anova in experiment 1 found that there was no significant effect of the cross-fall gradient on the ascending or descending walking speed. No increase of deviation relative to the cross-fall gradient was observed (Figure 7). In fact, in some cases, the amount of the deviation decreased. These results suggest that, for the range of the gradients tested, the cross-fall gradient did not affect the performance or perception of safety of the participants.

Before the experiment, the authors had expected an increase in deviation of visually impaired participants relative to the cross-fall gradient. However, the results (Figure 7) did not show such a proportionate relationship. One reason could be that the surface of the experiment site was covered by $40-\mathrm{cm}$ square concrete blocks, and as a result the participants were able to detect the edges of the blocks, thereby avoiding large deviation. This suggests that it would be useful to have some indication along the edge of platform to enable visually impaired people to walk safely along the platform. Nowadays, many stations have tactile paving about $1 \mathrm{~m}$ away from the platform edge, which is intended to warn visually impaired 
people of the platform edge being close by, but also is used as a guidance measure to walk along the platform. It may be necessary to have a similar guidance measure on humps, as well as on other parts of the platform, for visually impaired people to walk safely along the platform.

Figure 11 shows that generally the mobility restriction group had the highest failure rates in experiment 2, whereas the results of experiment 1 (Figure 8) show that the visually impaired group has the longest boarding/alighting time. It was also observed that for some participants in the visually impaired group in experiment 2, it took more than $20 \mathrm{~s}$ to board or alight. It is essential to remove barriers for such mobility impaired people, but it is also important, especially for high-frequency lines, to provide environments where visually impaired people feel safe and comfortable and can smoothly board or alight without hesitation.

This study has several limitations. One point is the sample size: the size of this study was small and, therefore, in order to set thresholds for design factors, more detailed investigations with larger sample sizes would be necessary. Another point is the choice of samples. As Stanford et al. (1997) mentioned, the selection of samples may affect the results. One approach for this issue would be to choose participants that represent the population. However, as the primary target of platform ramps is disabled people, who are not the majority, this approach would not be appropriate for the present study. Another approach would be that the samples should consist mainly of those who are disabled, but it is expected that the more severe the disability of the people, the more effects of design factors would be observed on their performance. It is true that using an underground system requires a certain level of mobility capabilities, and those with severe disability would not use an underground system on their own (Stanford et al., 1997). It is difficult to identify the underground passengers with the least mobility capabilities who should be considered in the design of platform humps, because platform humps, which would enable more disabled people to use the underground, have not yet been introduced and therefore there is no knowledge about their user profile. Thus, a careful approach would be required to reach a conclusion about the acceptable limit of design factors.

\section{Conclusion}

This study has investigated the effects of the slope and the cross-fall gradients of platform humps on disabled passengers. It was found that the slope gradients and cross-fall gradients tested did not greatly affect the performance of the participants' longitudinal walking. However, it is speculated that the slope gradient would have meant additional difficulty to board/alight the train from/onto a slope. Therefore, it might be thought advisable that the lower end of the slope reaches an adjacent door when the distance between doors is short. As the slope within the range of the tested gradients, which is $6.9 \%(1: 14)$ or less, did not largely affect the performance and perception of safety of the participants, one solution is to increase the slope gradient so that the slope finishes before reaching an adjacent door.

\section{Acknowledgements}

This study was commissioned and supported by London Underground Limited. The authors would like to thank Ffion Grant and Alan Jones at London Underground Limited for their various support. The role of the sponsor was to provide the experiment variables at the design stage only. Note that a summary of this work was presented at the Transed 2010 conference. The authors would like to thank the secretariat of the conference for granting permission to present an improved and enhanced version in this journal.

\section{REFERENCES}

Atkins (2004) Significant Steps. Department for Transport,

London, UK.

BSI (2009) BS 8300:2009 Design of buildings and their approaches to meet the needs of disabled people - code of practice. BSI, London, UK.

Canale I, Felici F, Marchetti M and Ricci B (1991) Ramp length/ grade prescriptions for wheelchair dependent individuals. Paraplegia 29: 479-485.

Department of Justice (2010) 2010 ADA Standards for Accessible Design. US Department of Justice, Washington DC, USA.Section 405.2.

DfT and TS (Department for Transport and Transport Scotland) (2011) Accessible Train Station Design for Disabled People: A Code of Practice, version 03. Department for Transport, London, UK.

HMG (Her Majesty's Government) (2010) Rail Vehicle Accessibility Regulations 2010. Her Majesty's Stationery Office, London, UK, Statutory Instrument 2010 No. 432.

Ishida T, Takemoto H, Ishida S et al. (2006) Evaluation of sidewalk unevenness based on wheelchair travelling resistance. Transportation Research Record 1956, 68-75.

Kim C, Lee D, Lee J, Kwon S and Chung M (2010) Effects of ramp slope and height on usability and physiology during wheelchair driving. Proceedings of the Human Factors and Ergonomics Society 54th Annual Meeting, San Francisco. Human Factors and Ergonomics Society, Santa Monica, CA, USA, pp. 698-702.

Leake GR, May AD and Parry T (1991) An Ergonomic Study of Pedestrian Areas of Disabled People. Transport and Road Research Laboratory, Wokingham, Berkshire, UK, Contractor Report 184. 
Stanford JA, Story MF and Jones ML (1997) An analysis of the effects of ramp slope on people with mobility impairments. Assistive Technology 9(1): 22-33.

Steinfeld E, Schroeder S and Bishop M (1979) Accessible Buildings for People with Walking and Reaching
Limitations. U.S. Government Printing Office for U.S. Department of Housing and Urban Development, Washington, DC, USA.

Templer JA (1992) The Staircase: Studies of Hazards, Falls, and Safer Design. MIT Press, Massachusetts, USA, pp. 44-46.

\section{WHAT DO YOU THINK?}

To discuss this paper, please email up to 500 words to the editor at journals@ice.org.uk. Your contribution will be forwarded to the author(s) for a reply and, if considered appropriate by the editorial panel, will be published as discussion in a future issue of the journal.

Proceedings journals rely entirely on contributions sent in by civil engineering professionals, academics and students. Papers should be 2000-5000 words long (briefing papers should be 1000-2000 words long), with adequate illustrations and references. You can submit your paper online via www.icevirtuallibrary.com/content/journals, where you will also find detailed author guidelines. 